\title{
The 25(OH)D3, but Not 1,25(OH)2D3 Levels Are Elevated in IBD Patients Regardless of Vitamin D Supplementation and Do Not Associate with Pain Severity or Frequency
}

\author{
Anna Zielińska ${ }^{1}\left(\right.$, Aleksandra Sobolewska-Włodarczyk ${ }^{2}$, Maria Wiśniewska-Jarosińska ${ }^{2}$, Anita Gąsiorowska ${ }^{2}$, \\ Jakub Fichna ${ }^{1}$ (D) and Maciej Sałaga ${ }^{1, *(\mathbb{D})}$ \\ 1 Department of Biochemistry, Faculty of Medicine, Medical University of Lodz, Mazowiecka 6/8, \\ 92-215 Lodz, Poland; ania.zielinska0122@gmail.com (A.Z.); jakub.fichna@umed.lodz.pl (J.F.) \\ 2 Department of Gastroenterology, Faculty of Medicine, Medical University of Lodz, Plac Gen. Józefa Hallera 1, \\ 90-647 Lodz, Poland; olasobolewska1@poczta.onet.pl (A.S.-W.); majkawj@bmp.net.pl (M.W.-J.); \\ anita.gasiorowska@umed.lodz.pl (A.G.) \\ * Correspondence: salaga.maciej@gmail.com; Tel.: +48-42-272-5707; Fax: +48-42-272-5694
}

check for updates

Citation: Zielińska, A.; Sobolewska-Włodarczyk, A.; Wiśniewska-Jarosińska, M.; Gąsiorowska, A.; Fichna, J.; Sałaga, M. The 25(OH)D3, but Not 1,25(OH)2D3 Levels Are Elevated in IBD Patients Regardless of Vitamin D

Supplementation and Do Not Associate with Pain Severity or Frequency. Pharmaceuticals 2021, 14, 284. https://doi.org/10.3390/ ph14030284

Academic Editor: Simona Bertoni

Received: 27 February 2021

Accepted: 19 March 2021

Published: 22 March 2021

Publisher's Note: MDPI stays neutral with regard to jurisdictional claims in published maps and institutional affiliations.

Copyright: (c) 2021 by the authors. Licensee MDPI, Basel, Switzerland. This article is an open access article distributed under the terms and conditions of the Creative Commons Attribution (CC BY) license (https:// creativecommons.org/licenses/by/ $4.0 /)$.

\begin{abstract}
Due to its immunomodulatory effect, vitamin D has been associated with clinical parameters and outcomes in inflammatory bowel diseases (IBDs) which are chronic conditions of the gastrointestinal tract. Upon synthesis or digestion, vitamin $\mathrm{D}$ is metabolized in the liver to form $25(\mathrm{OH}) \mathrm{D} 3$, the major circulating metabolite. Further renal hydroxylation generates $1,25(\mathrm{OH}) 2 \mathrm{D} 3$, the most potent metabolite. Our aim was to examine the association between vitamin $\mathrm{D}$ levels, and its supplementation and pain intensity in 39 IBD patients and 33 healthy individuals. 25(OH)D3 and 1,25(OH)2D3 serum levels were measured. Each subject filled out visual analog scale (VAS) and Laitinen's pain assessment scales. Laboratory results were obtained, and disease activity was assessed. Linear regression was employed to investigate the correlation between $25(\mathrm{OH}) \mathrm{D} 3,1,25(\mathrm{OH}) 2 \mathrm{D} 3$ and pain intensity, clinical activity parameters, C-reactive protein, disease duration, and dietary habits. In IBD patients, 25(OH)D3 was increased, whereas 1,25(OH)2D3 was not. Vitamin D3 supplementation did not influence their levels. No correlation was found between pain scores, disease activity, inflammatory status, disease duration or dietary habits and both forms of vitamin D. Elevated 25(OH)D3 and normal 1,25(OH)D3 were found in IBD patients as compared to the controls. We discovered no effect from supplementation and no association between pain severity and vitamin D.
\end{abstract}

Keywords: vitamin D; inflammatory bowel diseases; Crohn's disease; ulcerative colitis; supplementation; deficiency

\section{Introduction}

Inflammatory bowel diseases (IBDs), including Crohn's disease (CD) and ulcerative colitis (UC), are chronic, disabling disorders affecting mostly the gastrointestinal (GI) tract. IBD symptomatology is diverse and non-specific. General symptoms (fever, weakness, chronic diarrhea and weight loss) are accompanied by precipitating inflammation and ulceration throughout the GI tract $[1,2]$. Chronic abdominal pain is a frequent symptom of IBD, with up to $70 \%$ of the patients reporting it during the exacerbation, and more than $30 \%$ during clinical remission of the disease [2,3]. Pain is a cause of decreased quality of life in IBD patients, especially since the relapsing course of the disease causes intermittent exacerbations of pain $[2,4]$. It can occur secondary to acute inflammation, adhesions, bowel obstruction or strictures, bowel dysmotility, intestinal fistulas and abscess formation, but also because of extraintestinal symptoms of IBD, such as arthritis, skin lesions, bone diseases or oral aphthous lesions [2,3]. Pain in IBD is also influenced by commonly experienced fatigue, psychological factors, prior surgeries and relapses or disease activity [3]. Aside from the abovementioned, pain may be caused by visceral hypersensitivity, changes in sensory pathways during active inflammation, bacterial overgrowth or concomitant 
irritable bowel syndrome [3,5]. Importantly, skeletal and muscle pain have been associated with vitamin D deficiency, another very common ailment in IBD patients [3,6], although no such association has been established in IBD so far.

Vitamin D level is one of the environmental factors that may influence predisposition to IBD or its course [7]. It has been suspected to play an important immunologic role in IBD, particularly due to its anti-inflammatory effects [1,7]. It regulates gut epithelial integrity, microbiota, immune barrier function and growth and function of $\mathrm{T}$ cells, mechanisms essential in the prevention and improvement of the disease's symptoms [1,6]. Vitamin $\mathrm{D}$ deficiency in IBD is much more prevalent than in the general population, and higher in CD than in UC [1]. It is due to small bowel inflammation, causing malabsorption of nutrients, frequent ileal resection affecting bile salt resorption, frequent defecations, dietary restrictions, sun avoidance during immune-suppressive therapies and spending more time indoors due to disease exacerbations $[1,8,9]$. The evidence that vitamin $\mathrm{D}$ supplementation cures or prevents IBD is uncertain. Despite the growing popularity of vitamin D supplements, inflammatory diseases are still on the rise [10]. Currently, there are no specific guidelines advising appropriate supplemental doses [6].

25-hydroxyvitamin D3 (25(OH)D3) is the inactive, but main circulating form of vitamin $\mathrm{D}[10,11]$. In the renal tubular epithelium, it is hydroxylated to a physiologically active form and is the most potent steroid hormone in the human body: 1,25-dihydroxyvitamin D3 $(1,25(\mathrm{OH}) 2 \mathrm{D} 3)$ [9-12]. There is a notion that levels of serum $25(\mathrm{OH}) \mathrm{D} 3$ are accurate reflections of vitamin D status. However, in autoimmune diseases, 1,25( $\mathrm{OH}) 2 \mathrm{D} 3$ levels may be elevated, while $25(\mathrm{OH}) \mathrm{D} 3$ is deficient or normal, so its measurement may not provide enough data on vitamin D status [10].

The aim of our study was to determine if there is an association between the vitamin $\mathrm{D}$ forms' levels and the severity of pain experienced by IBD patients. Moreover, we took a closer look at vitamin D levels in connection with vitamin D supplementation with over-the-counter (OTC) drugs as well as disease activity, the severity of inflammation measured with C-reactive protein (CRP), and disease duration.

\section{Results}

\subsection{Study Group}

The demographics, laboratory outcomes and disease characteristics of the study population are summarized in Table 1. A total of 39 IBD patients and 33 healthy controls were enrolled in the study. In the IBD group, the majority were male with no significant differences in age between the CD and UC patients. Their questionnaires and medical charts were reviewed, and their serum 25(OH)D3 and 1,25(OH)2D3 levels were measured and then compared with the control group's results.

Table 1. Socio-demographic and clinical data of inflammatory bowel disease (IBD) patients and healthy controls.

\begin{tabular}{|c|c|c|}
\hline & IBD Patients & Control Group \\
\hline Subjects, n (\%) & $\begin{array}{c}39 \\
\text { CD } 17(43.6 \%) \\
\text { UC } 22(56.4 \%)\end{array}$ & 33 \\
\hline $\begin{array}{c}\text { Sex } \\
\text { Men, n (\%) } \\
\text { Women, n (\%) }\end{array}$ & $\begin{array}{l}22(56.4 \%) \\
17(43.6 \%)\end{array}$ & $\begin{array}{l}15(45.5 \%) \\
18(54.5 \%)\end{array}$ \\
\hline Age, year & $35.74 \pm 13.61$ & $38.73 \pm 17.52$ \\
\hline BMI, $\mathrm{kg} / \mathrm{m}^{2}$ & $32.21 \pm 4.88$ & $24.45 \pm 4.05$ \\
\hline $\begin{array}{c}\text { Duration of disease, } \mathbf{n}(\%) \\
<5 \text { years } \\
5-10 \text { years } \\
10-15 \text { years } \\
>15 \text { years }\end{array}$ & $\begin{array}{c}13(33.3 \%) \\
10(25.6 \%) \\
9(23.1 \%) \\
7(19 \%)\end{array}$ & \\
\hline
\end{tabular}


Table 1. Cont.

\begin{tabular}{|c|c|c|}
\hline & IBD Patients & Control Group \\
\hline Resection, n (\%) & $6(15.4 \%)$ & \\
\hline Colostomy, n (\%) & $2(5.1 \%)$ & \\
\hline Extraintestinal symptoms, n (\%) & $23(59.1 \%)$ & \\
\hline Use of painkillers, $n(\%)$ & $13(33.3 \%)$ & \\
\hline NSAIDs & $12(30.8 \%)$ & $4(12.1 \%)$ \\
\hline Opioids-Tramadol & $1(2.6 \%)$ & \\
\hline \multicolumn{3}{|l|}{ Biological treatment, n (\%) } \\
\hline IFX & $33(84.6 \%)$ & \\
\hline ADA & $2(5.1 \%)$ & \\
\hline VDZ & $4(10.3 \%)$ & \\
\hline CDAI, points & $180.47 \pm 110.32$ & \\
\hline MAYO, points & $2.43 \pm 0.75$ & \\
\hline \multicolumn{3}{|l|}{ Vitamin D3 supplementation, n (\%) } \\
\hline None & $30(76.9 \%)$ & $32(97.0 \%)$ \\
\hline $1500 \mathrm{IU}$ & $3(7.7 \%)$ & \\
\hline $2000 \mathrm{IU}$ & $5(12.8 \%)$ & \\
\hline $4000 \mathrm{IU}$ & $1(2.6 \%)$ & $1(3.0 \%)$ \\
\hline Mean 25(OH)D3, ng/mL & $50.85 \pm 17.68$ & $30.73 \pm 8.65$ \\
\hline Mean 1,25(OH)2D3, pmol/L & $81.05 \pm 14.64$ & $85.84 \pm 2.10$ \\
\hline White blood cell count, $\times 10^{3} / \mu \mathrm{L}$ & $8.14 \pm 4.08$ & \\
\hline Red blood cell count, $\times 10^{6} / \mu \mathrm{L}$ & $4.57 \pm 0.54$ & \\
\hline Hemoglobin, g/dL & $12.91 \pm 3.01$ & \\
\hline Hematocrit, \% & $39.02 \pm 5.31$ & \\
\hline Platelet count, $\times 10^{3} / \mu \mathrm{L}$ & $358.08 \pm 154.76$ & \\
\hline Mean platelet volume, fL & $9.91 \pm 1.01$ & \\
\hline $\mathrm{CRP}, \mathrm{mg} / \mathrm{dL}$ & $9.71 \pm 14.74$ & \\
\hline
\end{tabular}

Abbreviations: ADA: Adalimumab; BMI: Body mass index; CD: Crohn's disease; CDAI: Crohn's Disease Activity Index; CRP: C-reactive protein; IFX: Infliximab; NSAID's: Non steroid anti-inflammatory drugs; UC: ulcerative colitis; VDZ: Vedolizumab.

\section{2. $25 \mathrm{OH} \mathrm{D} 3$ and $1,25(\mathrm{OH}) 2 \mathrm{D} 3$ Levels}

We discovered that serum 25(OH)D3 levels were significantly higher in the $\mathrm{CD}, \mathrm{UC}$ and IBD group in comparison to the healthy volunteers $(51.43 \pm 4.59,50.44 \pm 3.66$ and $50.85 \pm 2.83$ vs. $30.37 \pm 1.51$ in CD, UC, IBD and control, respectively; $p<0.0001)$. The differences between $C D$ patients and UC patients lacked statistical significance. On the other hand, serum 1,25(OH)2D3 was not different in IBD patients compared to healthy volunteers (76.64 $\pm 3.80,84.13 \pm 2.86$ and $81.06 \pm 2.34$ vs. $85.84 \pm 2.10$ in $C D, U C$, and IBD patients and the control, respectively; $p<0.0001$ ) (Figure 1).

\subsection{Vitamin D3 Supplementation}

Vitamin D3 supplementation (1500-4000 I.U./daily) with commercially available overthe-counter drugs did not influence serum levels of 25(OH)D3 (in CD: $49.34 \pm 5.16$ vs. $57.71 \pm 10.59$ without supplementation vs. supplemented; in UC: $49.04 \pm 4.38$ vs. 53.94 \pm 8.54 without supplementation vs. supplemented) and 1,25(OH)2D3 (in CD: $78.96 \pm$ 3.72 vs. $69.70 \pm 10.73$ without supplementation vs. supplemented; in UC: $84.03 \pm 2.19$ vs. $87.00 \pm 10.24$ without supplementation vs. supplemented). Data on the relation between vitamin D supplementation and serum 25(OH)D3 and 1,25 (OH)2D3 levels are shown in Figure 2. The number of participants who consumed vitamin D supplements in each study group was low; however, they reported daily supplementary intake of vitamin D (Table 1). 


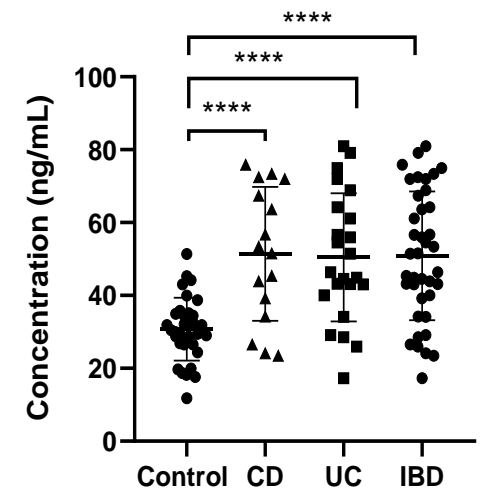

(a)

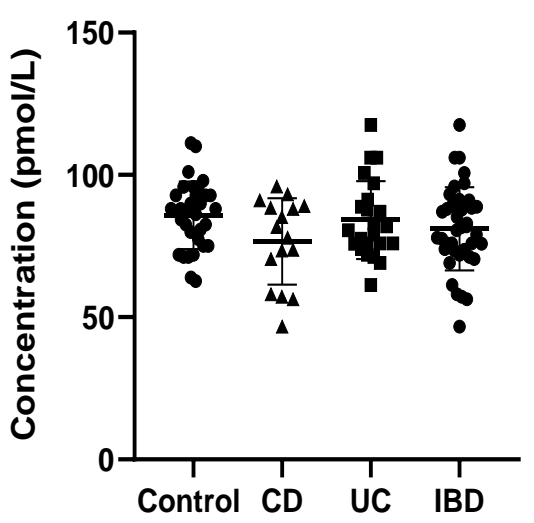

(b)

Figure 1. Serum concentrations of 25-hydroxy Vitamin D (25(OH) Vitamin D) (a) and 1,25-hydroxy Vitamin D (1,25(OH)2 Vitamin D) (b) in healthy subjects (control), in patients with Crohn's disease (CD) and ulcerative colitis (UC) and the whole test IBD patient group. **** $p<0.0001$, the difference between CD and UC was not statistically significant.

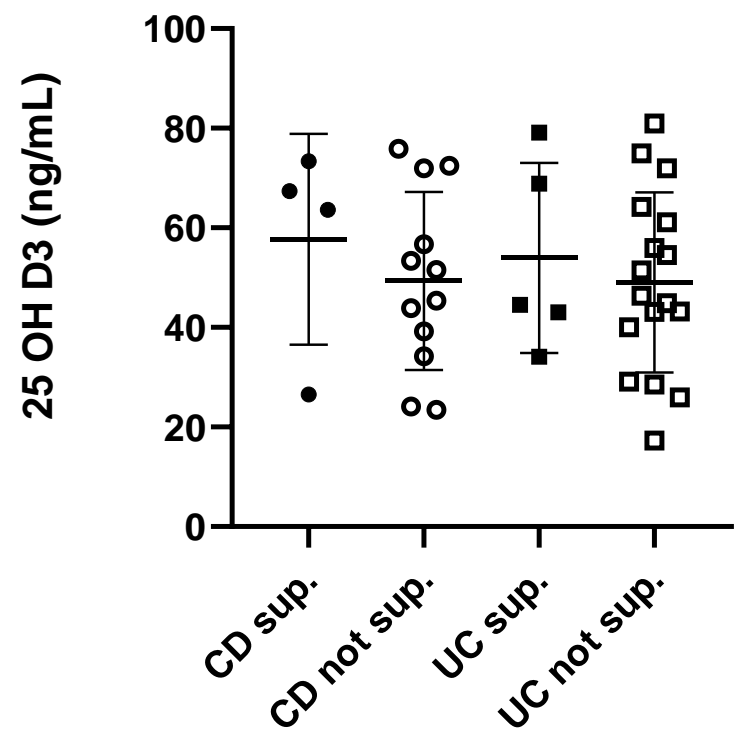

(a)

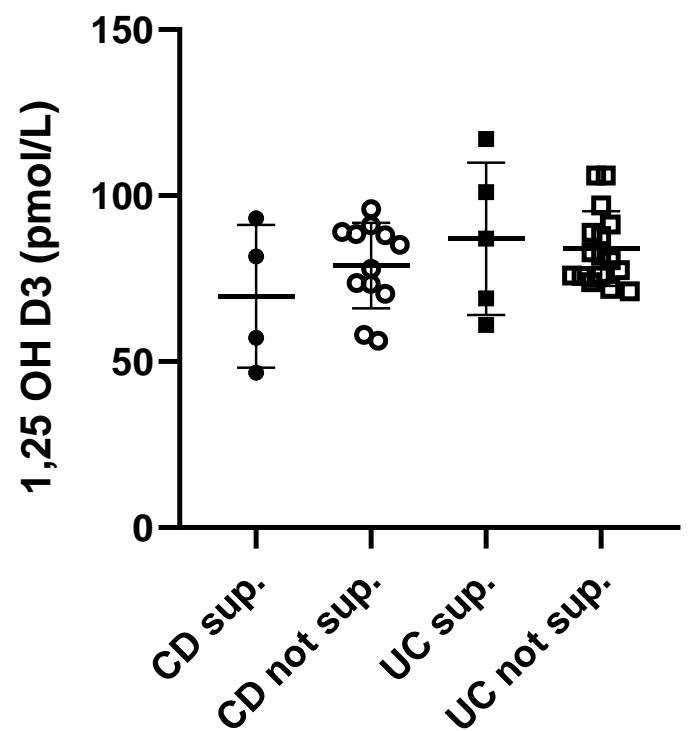

(b)

Figure 2. Serum concentrations of 25-hydroxy Vitamin D (25(OH) Vitamin D) (a) and 1,25-hydroxy Vitamin D (1,25(OH)2 Vitamin D) (b) in Crohn's disease (CD) and ulcerative colitis (UC) patients supplementing (sup.) or not supplementing (not sup.) vitamin D with over-the-counter (OTC) drugs.

\subsection{Disease Activity}

The majority of the $\mathrm{CD}$ patients presented with a mildly to moderately active disease, with a mean CDAI of $180.47 \pm 110.32$. In UC patients, the course of the disease was more severe and most of the UC patients were scored 3 in the endoscopic Mayo assessment. The mean endoscopic Mayo score was $2.43 \pm 0.75$. CDAI and Mayo scores were analyzed for association with serum $25(\mathrm{OH}) \mathrm{D} 3$ and 1,25(OH)2D3 levels. There were no significant correlations between 25(OH)D3 or 1,25(OH)2D3 and the CDAI or Mayo score (Figure 3). 


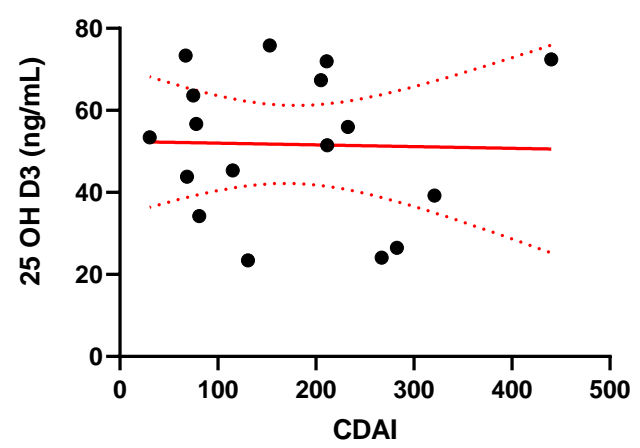

(a)

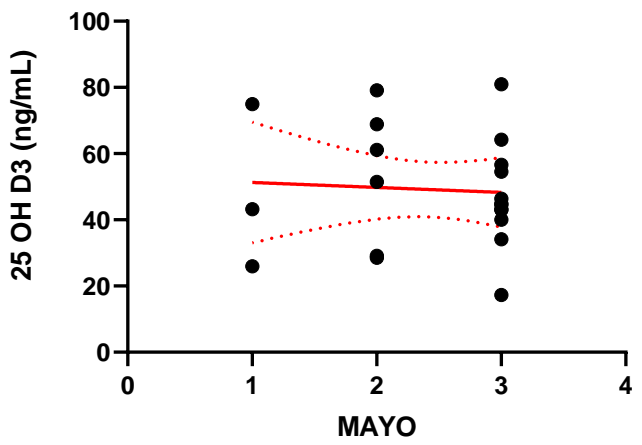

(c)

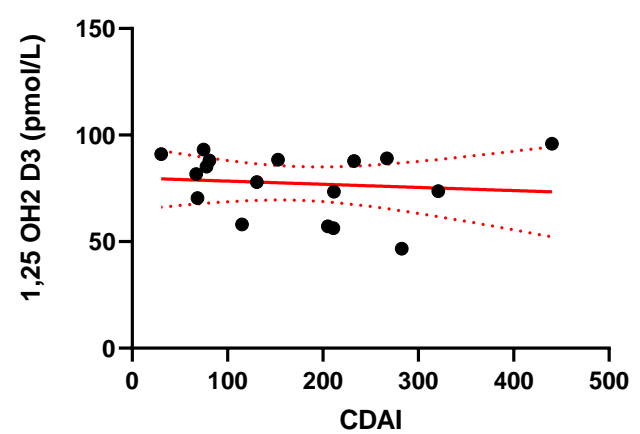

(b)

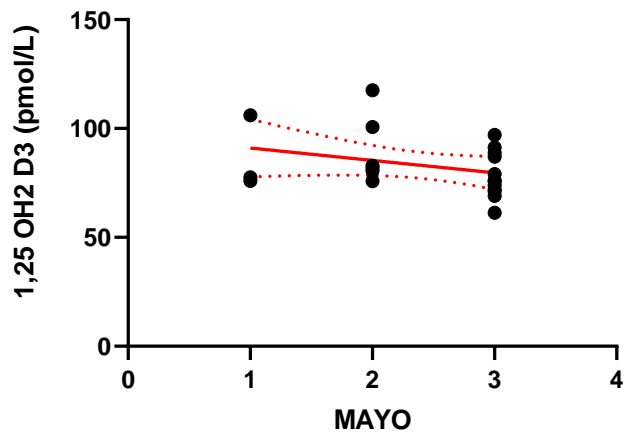

(d)

Figure 3. Correlation between serum concentration of 25-hydroxy Vitamin D (25(OH) Vitamin D) (a) and 1,25-hydroxy Vitamin D (1,25(OH)2 Vitamin D) (b) and the value of the Crohn's Disease Activity Index for Crohn's disease (CD) patients (c); and the value of Mayo score (c and d respectively) for ulcerative colitis (UC) patients (d).

\subsection{Inflammatory Status, Duration of the Disease and Pain}

Other individual variables were next analyzed for correlations with serum 25(OH)D3 or $1,25(\mathrm{OH}) 2 \mathrm{D} 3$ as described in the methods section. Since there were no significant differences in 25(OH)D3 and 1,25(OH)2D3 levels between CD and UC patients, these groups were combined for analyses.

The mean CRP in IBD patients in our study equaled 9.71 \pm 14.76 . The CRP levels did not correlate positively with serum 25(OH)D3 or 1,25(OH)2D3 levels (Figure 4).

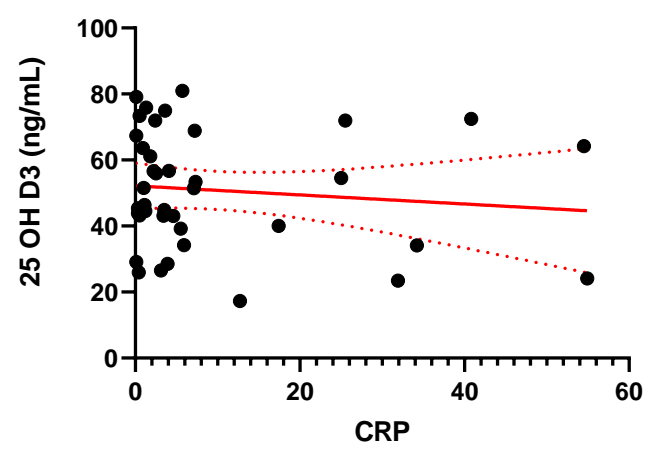

(a)

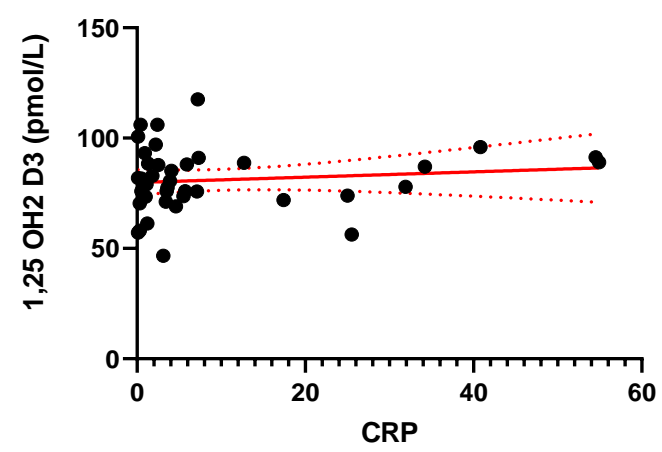

(b)

Figure 4. Correlation between serum concentration of 25-hydroxy Vitamin D (25(OH) Vitamin D) (a) and 1,25-hydroxy Vitamin D (1,25(OH)2 Vitamin D) (b) and the levels of C-reactive protein (CRP) in IBD patients. 
The duration of the disease also did not correlate significantly with the levels of 25(OH)D3 or 1,25( $\mathrm{OH}) 2 \mathrm{D} 3$ (Figure 5).

The pain experienced and subjectively assessed by IBD patients in the VAS pain scale and Laitinen's scale did not show statistically important correlation with both serum vitamin D forms [Figure 6]. The presence of pain was reported by $76.9 \%$ of patients (30/39). The mean scores for pain severity were similar for the CD and UC groups. For simplification of the statistical analysis, Laitinen's scale points have been added. The scale and mean results of the questionnaire are presented in Table 2.

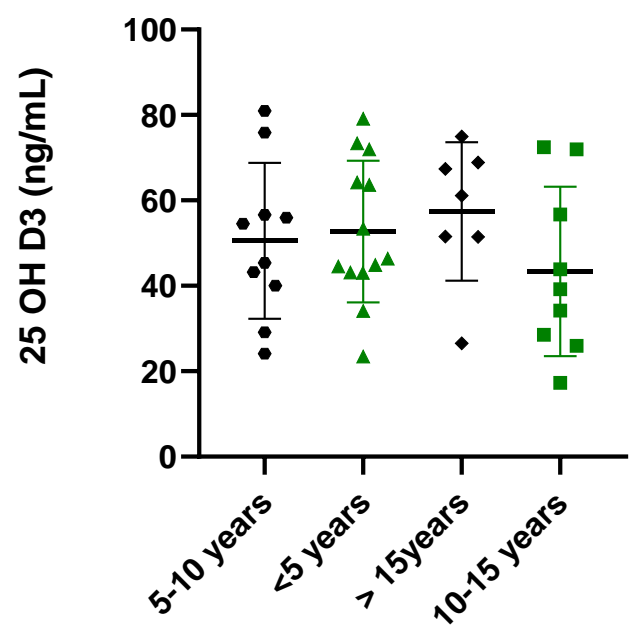

(a)

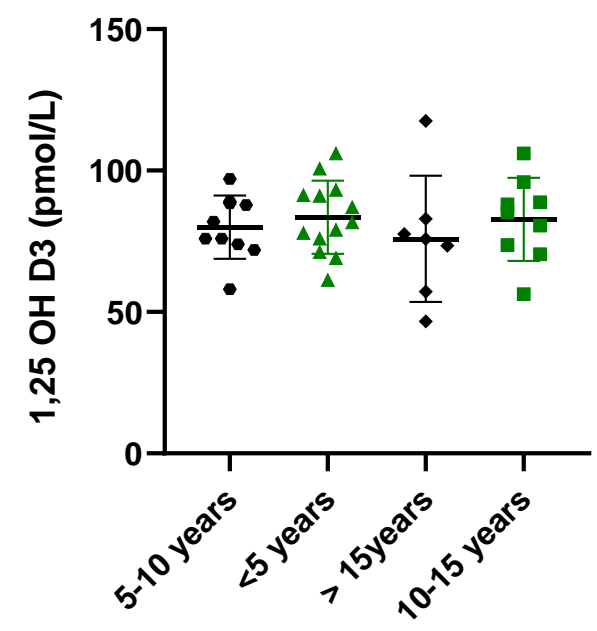

(b)

Figure 5. Serum concentration of 25-hydroxy Vitamin D (25(OH) Vitamin D) (a) and 1,25-hydroxy Vitamin D (1,25(OH)2 Vitamin D) (b) in IBD patients with respect to disease duration.

Table 2. Laitinen's pain scale results in enrolled IBD patients.

\begin{tabular}{|c|c|c|c|}
\hline Factor & Subjective Evaluation & Points & $\mathrm{n}, \%$ \\
\hline \multirow{5}{*}{ Pain Intensity } & Without pain & 0 & $13(33.3 \%)$ \\
\hline & Mild & 1 & $18(46.2 \%)$ \\
\hline & Strong & 2 & $8(20.5 \%)$ \\
\hline & Very strong & 3 & 0 \\
\hline & Not sustainable & 4 & 0 \\
\hline \multirow{5}{*}{ PAIN FREQUENCY } & Does not occur & 0 & $12(30.8 \%)$ \\
\hline & Periodical & 1 & $18(46.2 \%)$ \\
\hline & Frequent & 2 & $8(20.5 \%)$ \\
\hline & Very frequent & 3 & 0 \\
\hline & Continuous & 4 & $1(2.6 \%)$ \\
\hline \multirow{5}{*}{ PAINKILLERS' INTAKE } & Without medication & 0 & $13(33.3 \%)$ \\
\hline & Periodically & 1 & $24(61.5 \%)$ \\
\hline & Permanently- small doses & 2 & $2(5.1 \%)$ \\
\hline & Permanently- big doses & 3 & 0 \\
\hline & Permanently- very big doses & 4 & 0 \\
\hline \multirow{5}{*}{$\begin{array}{l}\text { MOTOR ACTIVITY } \\
\text { LIMITATION }\end{array}$} & None & 0 & $18(46.2 \%)$ \\
\hline & Partial & 1 & $12(30.8 \%)$ \\
\hline & Demanding partial help/making work difficult & 2 & $8(20.5 \%)$ \\
\hline & Demanding partial help/making work impossible & 3 & 0 \\
\hline & Demanding full help/preventing self sufficiency & 4 & $1(2.6 \%)$ \\
\hline
\end{tabular}




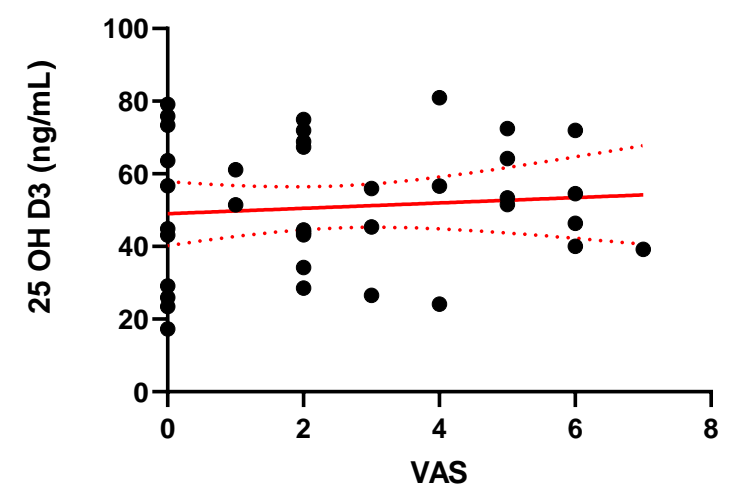

(a)

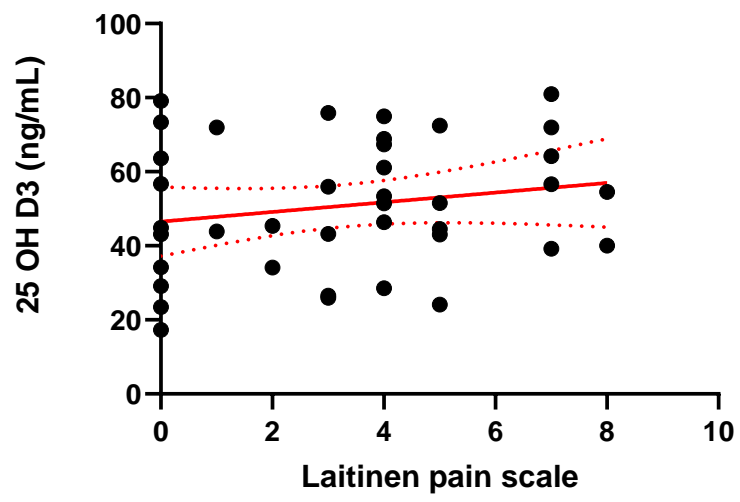

(c)

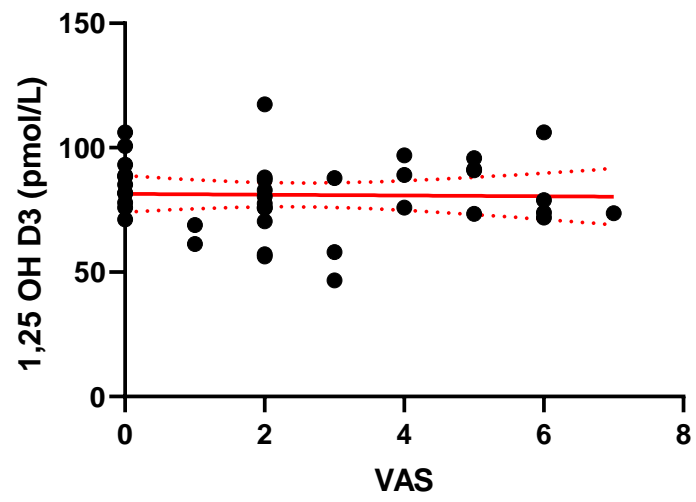

(b)

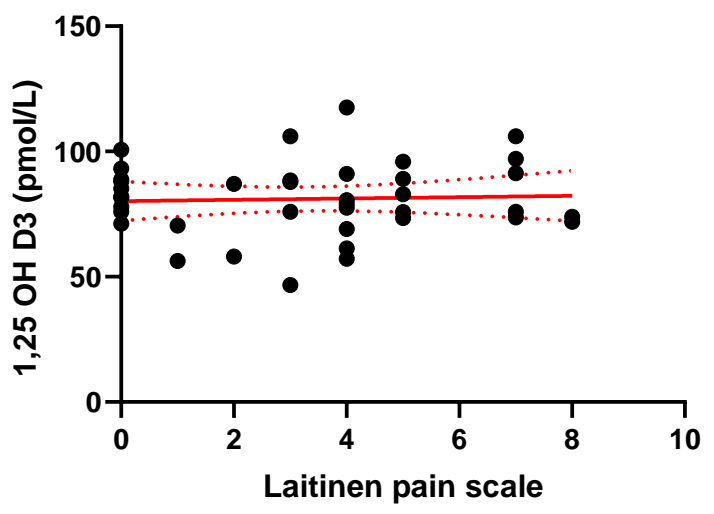

(d)

Figure 6. Correlation between serum concentration of 25-hydroxy Vitamin D (25(OH) Vitamin D) (a) and 1,25-hydroxy Vitamin D (1,25(OH)2 Vitamin D) (b) and the value of the visual analog scale (VAS) for quantification of disease-related pain (c); and the value of the modified Laitinen Pain Scale (c and d respectively) in IBD patients (d).

No correlation was found between the mean platelet volume, extraintestinal symptoms and body mass index. Dietary habits of IBD patients also did not influence the quantity of serum vitamin D (data presented in Supplementary Materials). Other initially investigated variables, comprising white blood cells (WBC), blood platelets (PLT), red blood cells (RBC), hematocrit (Hct) and hemoglobin, did not influence vitamin D serum levels or revealed statistical significance, and therefore were not included.

\section{Discussion}

We found increased 25(OH)D3 levels in IBD patients, and no difference in 1,25(OH)2D3 levels compared to healthy volunteers. Supplementation of vitamin D in enrolled IBD patients did not cause an increase in either metabolites. We did not find any association between vitamin $\mathrm{D}$ levels and disease activity, inflammatory status and pain severity or frequency.

Vitamin D supplementation is generally recommended for IBD, especially for the management of the bone disease. Not all studies, however, have recognized vitamin $D$ deficiency in IBD patients or the benefits of its intake [11-13]. For instance, Alkhouri et al. reported high vitamin D and zinc deficiency in both, 61 IBD patients and 61 sex and matched controls (62 and 75\%), with no correlation to the disease [14]. Steroid usage is often suspected to cause a reduction in bone mineral density (BMD) and vitamin D deficiency in IBD as they increase 24-hydroxylase activity which catabolizes 1,25(OH)2D3 
and 25(OH)D3 into their inactive metabolite: calcitroic acid. This was contradicted in a study by Lamb et al., in which bone mineral density was decreased even before steroid initiation [15]. Moreover, no correlation between increased incidence of UC and low sun exposure is reported, except for one between sunlight and CD [16]. In our study, blood samples were collected in a three-month period (between February and April); therefore we did not analyze the results separately by season for each IBD group. On the other hand, in a study performed by Ananthakrishnan et al., an increased IBD-related surgery risk was related to low serum 25(OH)D3 levels. CD patients, whose levels were normalized, were less susceptible to surgery than CD patients with continuously low serum levels of 25(OH)D3. They also presented a normalized CRP level. In UC patients, however, no correlation was found, which might be due to a stronger interaction of vitamin D in CD [17]. In another study performed by this group in 2012 on 72,719 women to find a risk of developing CD and UC, a group presenting with the highest predicted plasma vitamin $\mathrm{D}$ level had a much lower (40\% reduced) risk of developing CD, but no reduced risk of UC [18]. Contrarily, Nielsen et al., in a prospective cohort study of 120,013 individuals, described higher 25(OH)D3 levels as being associated with an increased risk of UC, but not of CD. However, genetically high plasma $25(\mathrm{OH}) \mathrm{D}$ levels (the combined $25(\mathrm{OH}) \mathrm{D}$ increasing allele score) were not associated with CD or UC. Thus, those results did not support a major role for vitamin D deficiency in the development of CD or UC [19].

The current method of defining vitamin $\mathrm{D}$ is flawed, as the level of $25(\mathrm{OH}) \mathrm{D} 3$ is not always reflective of the $1,25(\mathrm{OH}) 2 \mathrm{D} 3$ level. The latter is often increased when the former is normal or decreased, which could be a sign of changed vitamin D endocrine function. Our study showed higher serum 25(OH)D3 levels in IBD patients than in healthy controls, and comparable 1,25(OH)2D3 levels. This is contradictory to most studies that reported low 25(OH)D3 levels as a consequence of chronic inflammation or bacterial etiology [10]. Moreover, increased inflammation has been associated with enhanced extra-renal conversion of 25(OH)D3 to 1,25(OH)2D3 to support the anti-inflammatory immune response of the GI tract [1]. This extra-renal production of 1,25(OH)2D3 contributes to the depletion and low levels of 25(OH)D3. Because extra-renal 1,25(OH)2D3 production is dependent on $25(\mathrm{OH}) \mathrm{D} 3$ availability, the supplementation of vitamin D to increase $25(\mathrm{OH}) \mathrm{D} 3$ levels boosts extra-renal 1,25(OH)2D3 production [10]. Our results may imply a disruption in $1,25(\mathrm{OH}) 2 \mathrm{D} 3$ synthesis or a decreased response to parathyroid hormone, a dominant stimulant of $1,25(\mathrm{OH}) 2 \mathrm{D} 3$ synthesis in IBD patients. In the literature, inflammation is associated with lower PTH and 1,25(OH)2D3 concentrations [20]. In some studies, serum levels of $1,25(\mathrm{OH}) 2 \mathrm{D} 3$ were lower in IBD patients than in healthy patients due to improved bone mineral density (BMD) after remission of IBD, making 1,25(OH)2D3 normal [21].

The measurement of 1,25(OH)2D3 is rare, but this metabolite correlates inversely with BMD; it stimulates calcium absorption from the intestines, reabsorption in the kidneys and resorption in the bones, increasing bone loss and IBD severity [1,22]. Vanderschueren et al. described a combination of high $1,25(\mathrm{OH}) 2 \mathrm{D} 3$ and low $25(\mathrm{OH}) \mathrm{D} 3$ as a predictor of the poorest bone health [23]. Our patients presented opposite results.

Our study did not reveal any significant difference in $25(\mathrm{OH}) \mathrm{D} 3$ or $1,25(\mathrm{OH}) 2 \mathrm{D} 3$ levels between the CD and UC group. Abreu et al., on the contrary, demonstrated higher $1,25(\mathrm{OH}) 2 \mathrm{D} 3$ statuses in CD patients compared to UC patients [12]. The Nurses' Health Study proved that $25(\mathrm{OH}) \mathrm{D} 3$ protected patients from developing CD, but not UC [22]. In two prospective studies, CD patients with 25(OH)D3 levels lower than $30 \mathrm{ng} / \mathrm{mL}$ required more hospitalizations and surgeries than $\mathrm{CD}$ patients with higher $25(\mathrm{OH}) \mathrm{D} 3$ entry levels [21]. One of these studies included UC patients, in which the level of $<30 \mathrm{ng} / \mathrm{mL}$ resulted in treatment intensification and increased morbidity in a five-year follow up. The same result was obtained for CD patients [24].

In the current study, vitamin D supplementation influenced neither $25(\mathrm{OH}) \mathrm{D} 3$, nor $1,25(\mathrm{OH}) 2 \mathrm{D} 3$ levels of IBD patients. Most of the studies conducted to date reported that in IBD, oral supplementation may lead to vitamin D status improvements and benefits from the normalization of $25(\mathrm{OH}) \mathrm{D} 3$ levels [1]. In a study by Grunbaum et al., patients 
supplementing vitamin D supplements had higher levels than those who depended only on dietary intake. Yet, the levels of vitamin D still did not reach the desired values; about $50 \%$ of the patients and controls took supplements, but almost $60 \%$ did not achieve replete levels and supplementation was described as "disappointing". An increase was noted in the patients' group, but it was not statistically significant [25]. Furthermore, Suibhne et al. reported common vitamin $\mathrm{D}$ deficiency in $\mathrm{CD}$ patients in clinical remission, even though $40 \%$ of them were regularly supplementing vitamin D (200-400 IU a day) [26].

Many clinical trials analyzed the role of vitamin D3 supplementation in IBD activity. In a study by Narula et al., 34 CD patients in remission received 1000 or $10.000 \mathrm{IU}$ a day for 12 months. In this randomized double-blind study, the intention-to-treat analysis showed no significant differences between the two groups and the per protocol analysis showed a decreased risk of relapse after 12 months in the high-dose group [27]. In a double-blind placebo-controlled trial by Palmer et al., $94 \mathrm{CD}$ remitted patients received $1200 \mathrm{IU}$ of vitamin $\mathrm{D}$ a day or a placebo for one year. Both groups also supplemented $1200 \mathrm{mg}$ of calcium a day. The treatment insignificantly reduced CDAI [28]. In another randomized placebocontrolled study on $108 \mathrm{CD}$ patients in remission, individuals receiving $1200 \mathrm{IU}$ a day had increased 25(OH)D3 levels in comparison to the placebo group, as well as a reduced risk of relapse (29 to 13\% in one year); the results, however, were not statistically significant [29]. Yang et al. in a small open label pilot study evaluated 18 moderate CD patients and their vitamin D status, quality of life and clinical disease activity. They supplemented vitamin D3 for 24 weeks, starting from 1000 IU a day. The dose was increased by 1000 IU every two weeks until the patients were taking $5000 \mathrm{IU}$ a day or had serum 25(OH)D3 level $>40$ $\mathrm{ng} / \mathrm{mL}$. After the intervention, $78 \%$ of the patients presented CDAI scores below 150 and a decrease in CDAI score of 70 points or more. Moreover, their 25(OH)D3 levels and quality of life increased significantly [30]. Higher 25(OH)D3 levels were found to be associated with greater odds of remission with anti-TNF- $\alpha$ agents (adalimumab and infliximab) among patients with IBD in a study by Winter et al. Patients with normal vitamin D levels at the time of anti-TNF- $\alpha$ medication initiation had 2.64 increased odds of remission at three months compared to patients with low vitamin $\mathrm{D}$ levels. These findings suggest that vitamin D levels may influence the initial response to anti-TNF- $\alpha$ drugs and that low vitamin D levels could decrease the odds of remission [31].

There is strong evidence showing significantly lower $25(\mathrm{OH}) \mathrm{D}$ levels correlating with higher CDAI scores. Mildly diseased CD patients have vitamin D levels similar to the controls, while moderate to severe CD cases show significantly lower vitamin D levels [32].

In UC patients, a similar connection can be found. In a cross-sectional study, vitamin $D$ deficient, sufficient and insufficient groups were compared. The larger number of UC patients with a clinically active disease described by a six-point partial Mayo score were in the vitamin D deficient group, compared to the vitamin sufficient group. There continued to be a trend towards more active diseases with decreasing vitamin D levels [33]. In our study, we did not find statistical correlation between IBD activity and vitamin D levels. This is in accordance with a report by Hassan et al., who also found no association between serum vitamin D levels and disease activity [34].

Vitamin D can also be connected with inflammatory markers of colitis: CRP and fecal calprotectin. We took CRP levels into consideration and found no significance when correlating it with 25(OH)D3 and 1,25(OH)2D3 levels. A Korean study by Jun et al., concordantly to our research, established no association between 25(OH)D3 levels, CRP and partial Mayo scores in UC. In CD, a negative correlation was found between 25(OH)D3 and CRP levels, but administration of vitamin D did not improve the CRP level and disease indexes [35]. Contrarily, Garg et al. described a significant increase in vitamin D levels and an associated significant CRP reduction in active UC, inactive UC patients and non-UC probands. Nonetheless, the dose of supplemented cholecalciferol was rather high: 40.000 a week [36]. In another trial, $90 \mathrm{UC}$ patients in remission were randomized to receive 300.000 IU intramuscular vitamin D or $1 \mathrm{~mL}$ normal saline as a placebo. Before intervention and 
90 days after intervention, serum levels of $25(\mathrm{OH}) \mathrm{D} 3, \mathrm{PTH}$, calcium, ESR, and CRP were measured, and a significant decrease in CRP in the vitamin D group was reported [37].

Our study aimed at correlating disease duration with vitamin D levels and found that there is no correlation between the two. There is a limited body of literature concerning this association. A Japanese study by Tajika et al. found a relationship between vitamin D level and disease duration, CRP and CDAI, even though the CD patients did not present vitamin D levels lower than the control group. Moreover, it was also suggested that the duration of the disease and CDAI score can forecast the occurrence of vitamin D deficiency and that 25(OH)D3 levels should be assessed in patients who have had $\mathrm{CD}$ for a long time (>15 years) [38]. Suibhne et al. reported lower vitamin 25(OH)D levels to be associated with longstanding disease duration and smoking [26]. In a retrospective cohort study, Ulitsky et al. included $403 \mathrm{CD}$ patients with a mean disease duration of 15.5 years and 101 UC patients with a duration of 10.9 years. Of these patients, $49.8 \%$ were vitamin D deficient, with $10.9 \%$ having severe deficiency. In this study, vitamin D deficiency was associated with older age and older age at diagnosis, and also with increased CDAI [39]. The temporal causation of vitamin D deficiency and disease onset has not yet been endorsed. Subclinical disease can exist prior to a correct diagnosis. In children, for example, a change in growth pace can serve as a disease predictor and has been found to precede the formal diagnosis by $3-92$ months $[40,41]$.

In this study, neither pain severity, nor its frequency or influence on motor activity were significantly correlated with $25(\mathrm{OH}) \mathrm{D} 3$ or 1,25(OH)2D3 levels in IBD patients. There is only one study that investigated the association between vitamin D deficiency and pain severity in IBD and it is by Frigstad et al. This group also found no significant association between vitamin $\mathrm{D}$ level and pain severity. Pain severity has been, however, linked with increased disease activity in both UC and CD, but not with inflammatory markers, namely CRP and fecal calprotectin [3], which was not substantiated in our study. Previously, deficient vitamin D has been found in musculoskeletal diseases, such as osteomalacia, musculoskeletal pains and headaches [2,42]. In IBD, low vitamin D levels can be found during flares of the disease when the pain experience is increased due to aggravated symptoms and elevated visceral sensitivity [2,43]. Moreover, vitamin D reduces intestinal inflammation and inhibits prostaglandin E, which is a known inflammatory pain mediator [3,42]. Yet, inflammation is not always present when abdominal pain is reported, which was described in a study on abdominal pain in UC. In the absence of ongoing inflammation management, strategies should include interventions that target affective spectrum disorders and functional bowel disorders [44].

\section{Materials and Methods}

Ethical considerations: The study was conducted in accordance with the ethical principles of the 1975 Declaration of Helsinki and the study protocol was approved by the Committee of Bioethics of Medical University of Lodz, Poland (RNN/621/14/KB, 15 July, 2014).

Patients: This prospective observational cohort study was conducted in 39 IBD patients and 33 controls of Caucasian origin; $51.4 \%$ were male. The median age was 37 years (ranged 18-79 years). Subjects from the study group were patients qualified for biological treatment with infliximab, adalimumab and vedolizumab at the Department of Gastroenterology, Medical University of Lodz, Poland. Only adult patients with IBD were enrolled (CD nL'17 and UC nL'22).

The control group consisted of healthy subjects (the staff of the Department of Biochemistry, Medical University of Lodz, Poland, who voluntarily participated in the study) and was homogenous to the study group in terms of age, sex, and body mass index.

Inclusion criteria: The inclusion criteria for the study groups were based on the proper diagnosis according to clinical, radiological, endoscopic and histological criteria recommended by the European Crohn's and Colitis Organization (ECCO). 
Patients with a history of cardiovascular disease, pulmonary and kidney disease, allergy, diabetes, lichen planus, psoriasis, atopic dermatitis and other autoimmune skin lesions and those treated with anti-inflammatory drugs (except azathioprine and corticosteroids), antioxidants or statins were excluded from the study.

25(OH)D3 and 1,25(OH)2D3 serum quantification: After the participants from both groups gave written consent, $5 \mathrm{~mL}$ blood samples were collected into standardized serum tubes. The serum was immediately separated and quickly frozen at $-80^{\circ} \mathrm{C}$ and stored until use. In the IBD group, the sample was obtained in addition to blood specimens collected routinely on the day of the infusion of anti-tumor necrosis factor- $\alpha$ (anti-TNF- $\alpha$ ) agent (for standard blood work and clinical evaluation).

The total serum concentrations of 25(OH)D3 and 1,25(OH)2D3 were determined by the quantitative enzyme-linked immunosorbent assay (ELISA), using commercially available kits (OriGene, USA and Cusabio, USA respectively). Absorbances were read in a microplate reader at $450 \mathrm{~nm}$ (MicroPlate Reader; Bio-Rad, USA). For each detection, calibration blank tests have been taken into account. Each determination was carried out in duplicate in accordance with the manufacturers' instructions. All steps of the ELISA test were conducted at room temperature according to the assays' procedures.

The serum for the determination of 25(OH)D3 was not diluted, whereas the dilution of the serum for quantification of 1,25(OH)2D3 equaled 1:10.

The serum concentrations of $25(\mathrm{OH}) \mathrm{D} 3$ and $1,25(\mathrm{OH}) 2 \mathrm{D} 3$ were determined by calculating the mean absorbance values of reference standards, controls and patient samples and then using them to determine the corresponding concentration from the standard curve. In healthy persons, levels equal 25 to $40 \mathrm{ng} / \mathrm{mL}$ (62.4 to $99.8 \mathrm{nmol} / \mathrm{L}$ ) for 25(OH)D3 and 20 to $45 \mathrm{pg} / \mathrm{mL}$ (48 to $108 \mathrm{pmol} / \mathrm{L}$ ) for 1,25(OH)2D3 [45].

Demographic and clinical data: Each subject filled out a dietary, vitamin D supplementation and pain questionnaire (described below). Moreover, IBD patients were asked questions concerning the duration of the disease, extraintestinal symptoms and general wellbeing. The demographic data, including age, gender, body mass index, duration of the disease, the patient's age at diagnosis and previous biological treatments, data concerning alcohol and drug consumption and smoking history were collected from the patients and analyzed.

The laboratory evaluation of IBD patients included measurements of white blood cells (WBC), red blood cells (RBC), hemoglobin (Hgb), hematocrit (Htc), blood platelets (PLT), mean platelet volume (MPV) and C-reactive protein (CRP), determined using automatic devices. Measurements were performed on the day of the infusion of the anti-TNF agent (Table 1).

Assessment of disease activity: The disease activities of enrolled patients were assessed by abscesses or persistent symptoms despite intensive treatment was defined as severe $\mathrm{CD}$ using validated scales including the Crohn's Disease Activity Index (CDAI) for CD and the endoscopic Mayo Score for UC, respectively [46]. According to the European Crohn's and Colitis Organization (ECCO), the second European evidence-based consensus on the diagnosis and management of $\mathrm{CD}, \mathrm{CDAI}<150$ was defined as remission; CDAI 150-220 with no features of obstruction, fever, dehydration, abdominal mass or tenderness was defined as mild CD; CDAI 220-450 or intermittent vomiting, or weight loss $>10 \%$ or ineffective treatment for mild disease, or tender mass with no overt obstruction was defined as moderate CD; CDAI $<450$ or cachexia (body mass index (BMI) $<18 \mathrm{~kg} / \mathrm{m} 2$ ), or evidence of obstruction or abscess or persistent symptoms despite intensive treatment was defined as severe $C D$.

For UC, clinical remission was defined as a Mayo score of 0 ; mild UC was defined as Mayo Score of 1; moderate UC was defined as a Mayo score of 2; severe UC was defined as a Mayo score of 3 [47].

Assessment of pain experienced by the patient: All the patients were asked to fill out two pain questionnaires. For pain assessment, two scales were used: a visual analog scale (VAS), which is a validated, subjective measure for acute and chronic pain [48]. Scores 
were recorded by making a handwritten mark on a $10 \mathrm{~cm}$ line that represents a continuum between "no pain" at 0 and "worst pain" at 10 and Laitinen's pain scale, which allows for measuring pain intensity and simultaneously assessing other factors accompanying pain, namely frequency of pain occurrence, taking pain killers and limited motor activity (Table 2) [49].

Statistical analysis: The data were analyzed using the GraphPad Prism 8.0.1. (GraphPad Software, United States). Continuous demographic and biochemical data are presented as means \pm standard deviation (SD), and demographic categorical data are described with absolute frequencies and percentages. An analysis of variance (one-way ANOVA with repeated measures) was used to calculate the differences. Shapiro-Wilk's W test was used to test the distribution of the variables. Comparisons between groups were performed using the unpaired $\mathrm{t}$-test and $\mathrm{F}$ test to compare variances. A value of $p<0.05$ was considered statistically significant.

\section{Conclusions}

In our study, elevated 25(OH)D3 levels were associated with IBD, where the level of $1,25(\mathrm{OH}) 2 \mathrm{D} 3$ was similar to that of the healthy controls. This may imply a disruption in $1,25(\mathrm{OH}) 2 \mathrm{D} 3$ synthesis or a decreased response to parathyroid hormone, a dominant stimulant of $1,25(\mathrm{OH}) 2 \mathrm{D} 3$ synthesis in IBD patients. No reaction to vitamin D supplementation in the enrolled IBD patients was observed. This unexpected result may suggest diminished absorption or short longevity of ingested supplements. We did not find any association between vitamin D levels and pain severity or frequency. Further interventional studies are warranted to prove this hypothesis.

A limitation of our study was that it was performed on a small group of IBD patients. Further studies are warranted to confirm our observations, especially since they are contradictive to several previous studies. The major strength was that the study and control groups were homogenous and the study was multifactorial.

Supplementary Materials: The following are available online at https://www.mdpi.com/1424-8 $247 / 14 / 3 / 284 /$ s1, Figure S1. Serum concentration of 25-hydroxy Vitamin D (25(OH) Vitamin D) (a) and 1,25-hydroxy Vitamin D (1,25(OH)2 Vitamin D) (b) in IBD patients applying protein and carbohydrate- rich diet or balanced diet. Figure S2. Correlation between serum concentration of 25-hydroxy Vitamin D (25(OH) Vitamin D) (a) and 1,25-hydroxy Vitamin D (1,25(OH)2 Vitamin D) (b) and the values of body mass index (BMI). Figure S3. Correlation between serum concentration of 25-hydroxy Vitamin D (25(OH) Vitamin D) (a) and 1,25-hydroxy Vitamin D (1,25(OH)2 Vitamin D) (b) and the values of mean platelet volume (MPV) in IBD patients. Figure S4. Serum concentration of 25-hydroxy Vitamin D (25(OH) Vitamin D) (a) and 1,25-hydroxy Vitamin D (1,25(OH)2 Vitamin D) (b) in IBD patients with and without extraintestinal symptoms.

Author Contributions: Conceptualization, A.Z., J.F. and M.S.; methodology, A.Z., J.F. and M.S.; software, M.S.; validation, A.Z., A.S.-W., M.W.-J., A.G., J.F. and M.S.; formal analysis, A.S.-W., M.W.-J., A.G., J.F. and M.S.; investigation, A.Z.; resources, A.S.-W., J.F. and M.S.; data curation, A.S.-W., M.W.-J., A.G., J.F. and M.S.; writing—original draft preparation, A.Z., J.F. and M.S.; writing-review and editing, A.S.-W., M.W.-J., A.G., J.F. and M.S.; visualization, A.Z.; supervision, M.W.-J., A.G., J.F. and M.S.; project administration, M.S.; funding acquisition, J.F. and M.S. All authors have read and agreed to the published version of the manuscript.

Funding: Supported by grant from the Medical University of Lodz (\#503/1-156-04/503-11-001-19-00 to J.F.) and the Polish National Agency for Academic Exchange Bekker programme to M.S.

Institutional Review Board Statement: The study was conducted in accordance with the ethical principles of the 1975 Declaration of Helsinki and the study protocol was approved by the Committee of Bioethics of Medical University of Lodz, Poland (RNN/621/14/KB, 15 July 2014).

Informed Consent Statement: Informed consent was obtained from all subjects involved in the study.

Data Availability Statement: Not applicable. 
Conflicts of Interest: The authors declare no conflict of interest.

\section{References}

1. Fletcher, J.; Cooper, S.C.; Ghosh, S.; Hewison, M. The Role of Vitamin D in Inflammatory Bowel Disease: Mechanism to Management. Nutrients 2019, 11, 1019. [CrossRef]

2. Zielińska, A.; Sałaga, M.; Włodarczyk, M.; Fichna, J. Focus on Current and Future Management Possibilities in Inflammatory Bowel Disease-Related Chronic Pain. Int. J. Colorectal Dis. 2019, 34, 217-227. [CrossRef]

3. Frigstad, S.O.; Høivik, M.L.; Jahnsen, J.; Cvancarova, M.; Grimstad, T.; Berset, I.P.; Huppertz-Hauss, G.; Hovde, Ø.; Bernklev, T.; Moum, B.; et al. Pain Severity and Vitamin D Deficiency in Ibd Patients. Nutrients 2020, 12, 26. [CrossRef]

4. Ossum, A.M.; Palm, Ø.; Cvancarova, M.; Bernklev, T.; Jahnsen, J.; Moum, B.; Høivik, M.L. The Impact of Spondyloarthritis and Joint Symptoms on Health-Related Quality of Life and Fatigue in IBD Patients. Results from a Popu-lation-Based Inception Cohort (20-Year Follow-up in the Ibsen Study). Inflamm. Bowel Dis. 2020, 26, 114. [CrossRef] [PubMed]

5. Lamb, C.A.; Kennedy, N.A.; Raine, T.; Hendy, P.A.; Smith, P.J.; Limdi, J.K.; Hayee, B.; Lomer, M.C.E.; Parkes, G.C.; Selinger, C.; et al. British Society of Gastroenterology Consensus Guidelines on the Management of Inflammatory Bowel Disease in Adults. Gut 2019, 68, s1. [CrossRef] [PubMed]

6. Li, J.; Chen, N.; Wang, D.; Zhang, J.; Gong, X. Efficacy of Vitamin D in Treatment of Inflammatory Bowel Disease: A Meta-Analysis. Medicine 2018, 97, e12662-e. [CrossRef] [PubMed]

7. Burke, K.E.; Boumitri, C.; Ananthakrishnan, A.N. Modifiable Environmental Factors in Inflammatory Bowel Disease. Curr. Gastroenterol. Rep. 2017, 19, 1. [CrossRef]

8. Parian, A.; Limketkai, B.N. Dietary Supplement Therapies for Inflammatory Bowel Disease: Crohn's Disease and Ulcerative Colitis. Curr. Pharm. Des. 2015, 22, 180. [CrossRef] [PubMed]

9. Bancil, A.; Poullis, A. The Role of Vitamin D in Inflammatory Bowel Disease. Healthcare 2015, 3, 338. [CrossRef]

10. Mangin, M.; Sinha, R.; Fincher, K. Inflammation and Vitamin D: The Infection Connection. Inflamm. Res. 2014, 63, 803. [CrossRef]

11. Reich, K.M.; Fedorak, R.N.; Madsen, K.; Kroeker, K.I. Vitamin D Improves Inflammatory Bowel Disease Out-comes: Basic Science and Clinical Review. World J. Gastroenterol. 2014, 20, 4934. [CrossRef]

12. Abreu, M.T.; Kantorovich, Y.; Vasiliauskas, E.A.; Gruntmanis, U.; Matuk, R.; Daigle, K.; Chen, S.; Zehnder, D.; Lin, Y.C.; Yang, H.; et al. Measurement of Vitamin D Levels in Inflammatory Bowel Disease Patients Reveals a Subset of Crohn's Disease Patients with Elevated 1,25-Dihydroxyvitamin D and Low Bone Mineral Density. Gut 2004, 53, 1129. [CrossRef]

13. Bernstein, C.N.; Seeger, L.L.; Anton, P.A.; Artinian, L.; Geffrey, S.; Goodman, W.; Belin, T.R.; Shanahan, F. A Randomized, PlaceboControlled Trial of Calcium Supplementation for Decreased Bone Density in Corticosteroid-Using Patients with Inflammatory Bowel Disease: A Pilot Study. Aliment. Pharmacol. Ther. 1996, 10, 777. [CrossRef]

14. Alkhouri, R.H.; Hashmi, H.; Baker, R.D.; Gelfond, D.; Baker, S.S. Vitamin and Mineral Status in Patients with Inflammatory Bowel Disease. J. Pediatr. Gastroenterol. Nutr. 2013, 56, 89. [CrossRef]

15. Lamb, E.J.; Wong, T.; Smith, D.J.; Simpson, D.E.; Coakley, A.J.; Moniz, C.; Muller, A.F. Metabolic Bone Dis-ease Is Present at Diagnosis in Patients with Inflammatory Bowel Disease. Aliment. Pharmacol. Ther. 2002, 16, 1895. [CrossRef] [PubMed]

16. Nerich, V.; Jantchou, P.; Boutron-Ruault, M.-C.; Monnet, E.; Weill, A.; Vanbockstael, V.; Auleley, G.-R.; Balaire, C.; Dubost, P.; Rican, S.; et al. Low Exposure to Sunlight Is a Risk Factor for Crohn's Disease. Al-iment. Pharmacol. Ther. 2011, 33, 940. [CrossRef] [PubMed]

17. Ananthakrishnan, A.N.; Cagan, A.; Gainer, V.S.; Cai, T.; Cheng, S.C.; Savova, G.; Chen, P.; Szolovits, P.; Xia, Z.; de Jager, P.L.; et al. Normaliza-tion of Plasma 25-Hydroxy Vitamin D Is Associated with Reduced Risk of Surgery in Crohn's Disease. Inflamm. Bowel Dis. 2013, 19, 1921. [PubMed]

18. Ananthakrishnan, A.N.; Khalili, H.; Higuchi, L.M.; Bao, Y.; Korzenik, J.R.; Giovannucci, E.L.; Richter, J.M.; Fuchs, C.S.; Chan, A.T. Higher Predicted Vitamin D Status Is Associated with Reduced Risk of Crohn's Disease. Gastro-Enterology 2012, $142,482$. [CrossRef] [PubMed]

19. Lund-Nielsen, J.; Vedel-Krogh, S.; Kobylecki, C.J.; Brynskov, J.; Afzal, S.; Nordestgaard, B.G. Vitamin D and Inflammatory Bowel Disease: Mendelian Randomization Analyses in the Copenhagen Studies and UK Biobank. J. Clin. En-docrinol. Metab. 2018, 103, 3267. [CrossRef] [PubMed]

20. Augustine, M.V.; Leonard, M.B.; Thayu, M.; Baldassano, R.N.; de Boer, I.H.; Shults, J.; Denson, L.A.; DeBo-er, M.D.; Herskovitz, R.; Denburg, M.R. Changes in Vitamin D-Related Mineral Metabolism after Induction with An-ti-Tumor Necrosis Factor- $\alpha$ Therapy in Crohn's Disease. J. Clin. Endocrinol. Metab. 2014, 99, E991. [CrossRef] [PubMed]

21. Li, X.X.; Liu, Y.; Luo, J.; Huang, Z.D.; Zhang, C.; Fu, Y. Vitamin D Deficiency Associated with Crohn's Disease and Ulcerative Colitis: A Meta-Analysis of 55 Observational Studies. J. Transl. Med. 2019, 17, 1. [CrossRef]

22. Boden, S.D.; Kaplan, F.S. Calcium Homeostasis. Orthop. Clin. North Am. 1990, 21, 31-42. [CrossRef]

23. Vanderschueren, D.; Pye, S.R.; O’Neill, T.W.; Lee, D.M.; Jans, I.; Billen, J.; Gielen, E.; Laurent, M.; Claessens, F.; Adams, J.E.; et al. Active Vitamin D (1,25-Dihydroxyvitamin D) and Bone Health in Middle-Aged and Elderly Men: The European Male Aging Study (EMAS). J. Clin. Endocrinol. Metab. 2013, 98, 995. [CrossRef]

24. Kabbani, T.A.; Koutroubakis, I.E.; Schoen, R.E.; Ramos-Rivers, C.; Shah, N.; Swoger, J.; Regueiro, M.; Barrie, A.; Schwartz, M.; Hashash, J.G.; et al. Association of Vitamin D Level with Clinical Status in Inflammatory Bowel Disease: A 5-Year Longitudinal Study. Am. J. Gastroenterol. 2016, 111, 712. [CrossRef] [PubMed] 
25. Grunbaum, A.; Holcroft, C.; Heilpern, D.; Gladman, S.; Burstein, B.; Menard, M.; Al-Abbad, J.; Cassoff, J.; Mac-namara, E.; Gordon, P.H.; et al. Dynamics of Vitamin D in Patients with Mild or Inactive Inflammatory Bowel Disease and Their Families. Nutr. J. 2013, 12, 1. [CrossRef] [PubMed]

26. Suibhne, T.N.; Cox, G.; Healy, M.; O'Morain, C.; O'Sullivan, M. Vitamin D Deficiency in Crohn's Disease: Prevalence, Risk Factors and Supplement Use in an Outpatient Setting. J. Crohn's Colitis 2012, 6, 182. [CrossRef] [PubMed]

27. Narula, N.; Cooray, M.; Anglin, R.; Muqtadir, Z.; Narula, A.; Marshall, J.K. Impact of High-Dose Vitamin D3 Supplementation in Patients with Crohn's Disease in Remission: A Pilot Randomized Double-Blind Controlled Study. Dig. Dis. Sci. 2017, 62, 448. [CrossRef]

28. Palmer, M.T.; Weaver, C.T. Linking Vitamin D Deficiency to Inflammatory Bowel Disease. Inflamm. Bowel Dis. 2013, 19, 2245-2256. [CrossRef]

29. Jørgensen, S.P.; Agnholt, J.; Glerup, H.; Lyhne, S.; Villadsen, G.E.; Hvas, C.L.; Bartels, L.E.; Kelsen, J.; Chris-tensen, L.A.; Dahlerup, J.F. Clinical Trial: Vitamin D3 Treatment in Crohn's Disease A Randomized Double-Blind Place-bo-Controlled Study. Aliment. Pharmacol. Ther. 2010, 32, 377. [CrossRef]

30. Yang, L.; Weaver, V.; Smith, J.P.; Bingaman, S.; Hartman, T.J.; Cantorna, M.T. Therapeutic Effect of Vitamin d Supplementation in a Pilot Study of Crohn's Patients. Clin. Transl. Gastroenterol. 2013, 4, e33. [CrossRef]

31. Winter, R.W.; Collins, E.; Cao, B.; Carrellas, M.; Crowell, A.M.; Korzenik, J.R. Higher 25-hydroxyvitamin D levels are associated with greater odds of remission with anti-tumour necrosis factor- $\alpha$ medications among patients with inflammatory bowel diseases. Aliment. Pharmacol. Ther. 2017, 45, 653.

32. Joseph, A.J.; George, B.; Pulimood, A.B.; Seshadri, M.S.; Chacko, A. 25 (OH) Vitamin D Level in Crohn's Dis-ease: Association with Sun Exposure \& Disease Activity. Indian J. Med. Res. 2009, 130, 133. [PubMed]

33. Blanck, S.; Aberra, F. Vitamin D Deficiency Is Associated with Ulcerative Colitis Disease Activity. Dig. Dis. Sci. 2013, 58, 1698. [CrossRef] [PubMed]

34. Hassan, V.; Hassan, S.; Seyed-Javad, P.; Ahmad, K.; Asieh, H.; Maryam, S.; Farid, F.; Siavash, A. Association between Serum 25 $(\mathrm{OH})$ Vitamin D Concentrations and Inflammatory Bowel Diseases (IBDS) Activity. Med. J. Malaysia 2013, 68, 34.

35. Jun, J.C.; Yoon, H.; Choi, Y.J.; Shin, C.M.; Park, Y.S.; Kim, N.; Lee, D.H.; Kim, J.S. The Effect of Vitamin D Ad-ministration on Inflammatory Markers in Patients with Inflammatory Bowel Disease. Intest. Res. 2019, 17, 210. [CrossRef]

36. Garg, M.; Hendy, P.; Ding, J.N.; Shaw, S.; Hold, G.; Hart, A. The Effect of Vitamin D on Intestinal Inflammation and Faecal Microbiota in Patients with Ulcerative Colitis. J. Crohn's Colitis 2018, 12, 963. [CrossRef] [PubMed]

37. Sharifi, A.; Hosseinzadeh-Attar, M.J.; Vahedi, H.; Nedjat, S. A Randomized Controlled Trial on the Effect of Vitamin D3 on Inflammation and Cathelicidin Gene Expression in Ulcerative Colitis Patients. Saudi J. Gastroenterol. 2016, $22,316$.

38. Tajika, M.; Matsuura, A.; Nakamura, T.; Suzuki, T.; Sawaki, A.; Kato, T.; Hara, K.; Ookubo, K.; Yamo, K.; Kato, M.; et al. Risk Factors for Vitamin D Deficiency in Patients with Crohn's Disease. J. Gastroenterol. 2004, 39, 527. [CrossRef]

39. Ulitsky, A.; Ananthakrishnan, A.N.; Naik, A.; Skaros, S.; Zadvornova, Y.; Binion, D.G.; Issa, M. Vitamin D Deficiency in Patients with Inflammatory Bowel Disease: Association with Disease Activity and Quality of Life. J. Parenter. Enter. Nutr. 2011, 35, 308. [CrossRef]

40. Limketkai, B.N.; Bechtold, M.L.; Nguyen, D.L. Vitamin D and the Pathogenesis of Inflammatory Bowel Dis-ease. Curr. Gastroenterol. Rep. 2016, 18, 1-8. [CrossRef]

41. Kanof, M.E.; Lake, A.M.; Bayless, T.M. Decreased Height Velocity in Children and Adolescents before the Di-agnosis of Crohn's Disease. Gastroenterology 1988, 95, 1523. [CrossRef]

42. Liu, X.; Nelson, A.; Wang, X.; Farid, M.; Gunji, Y.; Ikari, J.; Iwasawa, S.; Basma, H.; Feghali-Bostwick, C.; Rennard, S.I. Vitamin D Modulates Prostaglandin E2 Synthesis and Degradation in Human Lung Fibroblasts. Am. J. Respir. Cell Mol. Biol. $2014,50,40$.

43. Von Känel, R.; Müller-Hartmannsgruber, V.; Kokinogenis, G.; Egloff, N. Vitamin D and Central Hypersensi-tivity in Patients with Chronic Pain. Pain Med. 2014, 15, 1609. [CrossRef] [PubMed]

44. Coates, M.D.; Lahoti, M.; Binion, D.G.; Szigethy, E.M.; Regueiro, M.D.; Bielefeldt, K. Abdominal Pain in Ul-cerative Colitis. Inflamm. Bowel Dis. 2013, 19, 2207. [CrossRef] [PubMed]

45. Test: 1,25-Dihydroxvitamin D (1,25-D) (MPKB). Available online: https://mpkb.org/home/tests/125d (accessed on 13 January 2021).

46. Walsh, A.; Palmer, R.; Travis, S. Mucosal Healing as a Target of Therapy for Colonic Inflammatory Bowel Dis-ease and Methods to Score Disease Activity. Gastrointest. Endosc. Clin. North Am. 2014, 24, 367-378. [CrossRef] [PubMed]

47. Vashist, N.M.; Samaan, M.; Mosli, M.H.; Parker, C.E.; Macdonald, J.K.; Nelson, S.A.; Zou, G.Y.; Feagan, B.G.; Khanna, R.; Jairath, V. Endoscopic Scoring Indices for Evaluation of Disease Activity in Ulcerative Colitis. Cochrane Database Syst. Rev. 2018. [CrossRef]

48. Goddard, G.; Karibe, H.; McNeill, C. Reproducibility of Visual Analog Scale (VAS) Pain Scores to Mechanical Pressure. Cranio 2004, 22, 250. [CrossRef] [PubMed]

49. Janusz, K. Kinesiophobia (Fear of Movement) Level Among Patients with Diagnosis of Cervicogenic Headache Poziom Kinezjofobii (Strach Przed Ruchem) u Pacjentów Ze Zdiagnozowanym Szyjnopochodnym Bólem Głowy Janusz Kocjan Medical University of Silesia. School M 2017, 7, 390. 